\title{
STUDENTS' REFLECTION ON CO-DESIGN: A CROSS-DISCIPLINARY COLLABORATION BETWEEN TWO SADC COUNTRIES
}

\author{
K. J. Mchunu* \\ e-mail: khayam@dut.ac.za \\ S. Moodley* \\ e-mail: sunthram@dut.ac.za \\ Department of Fashion and Textiles \\ Durban University of Technology \\ Durban, South Africa,
}

\section{ABSTRACT}

This reflective article responds to the question: "What values and lessons can be gained from codesign in a culturally and disciplinarily diverse cross-university student project?" The Polar Project is regarded as just such an initiative and was intended to boost innovative product development across fields of study between two higher education institutions (HEIs) located in Southern African Development Community (SADC) region countries.

As lecturers, facilitators and mentors, the article's authors adopted a qualitative and interpretive approach for analysing student "reflections-in-action", using both reports and reflective questionnaires during the project's co-design process. We formulated our own analysis methods for the process of critical reflection, based on Schön's (1987) "reflection-on-action" model, to establish a way forward for the project. Through these reflections, the following critical themes were identified: (1) rewards for cross-cultural exchange; (2) multiple appreciations for collaboration; and (3) communication and miscommunication in cross-disciplinary groups.

These themes provide an account of the practical implications for activities geared towards the agenda of internationalising higher educational practices, such as those applied in conducting this project. The contribution we hope to make is that, as HEls enter onto internationalisation agendas, the voices and experiences of students should be recognised if, as important beneficiaries of the university system, they are to be properly considered.

Keywords: co-design, reflection-in-action, reflection-on-action, student voice, internationalisation of higher education

\section{INTRODUCTION AND CONTEXT}

"Twice a day, on his way to and from school, little Charlie Bucket had to walk right past the gates of the factory. And every time he went by, he would begin to walk very, very slowly, and he would hold his nose high in the air and take long deep sniffs of the gorgeous chocolatey smell all around 
him. Oh, how he loved that smell! And oh, how he wished he could go inside the factory and see what it was like!" (Roald Dahl, Charlie and the Chocolate Factory, 1964)

In this article, we reflect on a student project conducted between Namibian- and South Africanbased universities, and discuss the values and lessons gained from the project's co-design process. In our positions as mentors, facilitators and researchers in the project, we discuss how student "reflection-in-action" (Schön 1983; 1987) for this cross-disciplinary project assisted us in assessing the values and learnings, which contribute to and support further such project development.

The values and learnings present in the project were identified by undergoing our own "reflection-on-action" process (Schön 1983; 1987), and framing this reflection within the bounds of the question: "What values and lessons can be gained through co-design in a culturally and disciplinarily diverse cross-university student project?"

The project operated under the name "Polar Project", and it is worth noting that, South Africa and Namibia are not polar opposites both geographically, and in many respects culturally and historically, both countries like many other countries in the African continent share a similar history of colonisation. Rather, the name chosen, figuratively references the diverse fields of study in which the students who participated in this project were engaged.

As our university embarks on its course of internationalising higher education, we hope with this article to contribute to the field of study in which the student voice is treated as an imperative for such exercises. In this regard, we discuss and promote "reflection-in-action" as a tool through the use of which this voice may be heard and fully considered

From an "internationalisation of higher education" perspective, this article is an example of the use of African intellectual cross-culturalism, or "métissage", as promoted by Hagenmeier et al. (2017), with their assertion that "all African states should collaborate to develop the next generation of professionals, technocrats and intellectuals who are capacitated to solve the continent's challenges" (Hagenmeier et al. 2017, 99).

Internationalisation in higher education is generally regarded as "a process that involves increasing the range of international activities within universities and between universities" (Robson 2011). One of the motivations for internationalisation in universities is the globalisation of business and communication patterns, and the emergence of a "new knowledge economy" (Haigh 2002).

While much of the literature on internationalisation focuses on incoming international students and the challenges for teaching and learning associated with the increasing diversity of the student population (Robson 2011); our institution, as will be shown in this article, 
responded by exploring the opportunity arising from an international research collaboration "to promote cultural diversity and foster intercultural understanding, respect and tolerance among people" involved in such a project (Robson 2011, 621).

For the Polar Project, we adapted the goal of internationalisation of higher education and focused on "intersections in education" and "teamwork in multiple disciplines". Educational intersections are described by Tintiangco-Cubales et al. (2010) as powerful collaborative spaces where people of divergent starting points could dialogue; Reich and Reich (2006) advocate that "each participant in interdisciplinary collaborations must value diversity, develop the capacity for self-assessment, work towards understanding one's own disciplinary culture, and be sensitive to the dynamics inherent when cultures interact".

Interdisciplinary collaborations are understood to capitalise on a diversity of perspectives and practices that each discipline offers in hopes of providing innovative solutions to multifaceted problems (Reich and Reich 2006). This project, therefore, became an instance of applying "métissage" and drawing from its application the challenges and the rewards.

The Polar Project was conducted over a 12-month period and, in addition to internalisation, it was also prompted by the thread of social innovation currently being followed by our institution. The project was a collaborative initiative between the Durban University of Technology (DUT), and the Design and Technology Centre (DTC) based at a university in Windhoek.

The project was conceived when the Research Officer for DUT's Faculty of Arts and Design (FAD) met with the co-founder of Windhoek's DTC during a 2016 conference hosted in Cape Town. Subsequent to this meeting, in 2017, DUT's Fashion Department partnered with the Windhoek-based faculty in a multidisciplinary pilot student exchange programme to boost innovative product development across the fields of study between the two cities.

The objective of the project was to promote international cooperation and foster international development through staff and student experience. The project which emerged from this engagement took place trans- the two SADC-region countries, with students and disciplines collaborating in the cross-cultural and cross-disciplinary experience across national borders.

The reflection originating from the project builds on the ongoing dialogue concerning innovative approaches for enhancing student experience in the twenty-first century, as laid out by Coates et al. (2016). The article therefore indicates how dialogue "about" students can transform into dialogue "with" students, particularly in student-led exercises such as the Polar Project.

The outcomes of this collaborative project coincide, moreover, with the vision and mission 
of DUT, which is to be "a preferred university for developing leadership in technology and productive citizenship". DUT's vision is divided into two strategic strands of student-centricity and engagement, which form part of the institution's strategic plan (2017-2019). These are further divided into four Strategic Focus Areas (SFAs) for building and development: (1) sustainable student communities for living and learning; (2) research and innovation in development; (3) organisational learning; and (4) institutional sustainability. Each SFA has strategic objectives set for their frameworks of action. The Polar Project fits succinctly into the focus area for building sustainable living and learning student communities. This particular SFA has objectives which:

- Provide accessible and enabling living and learning environments, which promote student success, and advance their intellectual, psychosocial and emotional growth.

- Develop and strengthen ethical citizenship and leadership skills amongst students, and build on their sense of critical social, economic, environmental and political identity, including that of being global citizens.

- Provide innovative teaching, learning and assessment for students, which focus on demanddriven and user-oriented programmes to accommodate their diverse needs, and enhance graduate quality.

- Deepen the innovative use of technology to improve the quality of student learning, teaching and assessment.

For the purposes of this article, we focus on the DUT's portion of the project, and therefore concentrate primarily on the reflection-in-action of the DUT student body, as also on our own reflection-on-action, as educators and co-authors of this review.

The article focuses initially on the theory of reflective practice in order to provide a theoretical context regarding how the ideas explored relate specifically to the Polar Project. Next, the positionalities of all participants in the Polar Project are discussed, followed by the design process engaged in by the students as part of the project.

Following this, we analyse student reflections on the project, gathered in the form of reports and questionnaires, to thematically formulate the values and learning gained by them through their participation in the project. The analysis provided is complemented by our own reflections on the project's outcomes in order to assess how the Polar Project, which was largely exploratory in nature, can be developed in future. In the final section of the article, we sum up by presenting our findings and discussion regarding the project. 


\section{REFLECTION-IN-ACTION AND REFLECTION-ON-ACTION}

Reflective practice, as an approach in the field of design, is grounded in Schön's notion of the designer as a reflective practitioner (Bannon and Ehn 2012). The concept acknowledges the "complexity and chaos" of design situations, and we find it of value to pay attention to the ways which this "complexity and chaos" is addressed (Bannon and Ehn 2012, 46). Higgins (2011), in addition, advocates that "... reflection encourages students to be willing and able to question, explore and critique ways of behaving and thinking as they engage in [...] experiences."

Quayle and Paterson $(1989,30)$ pose the question: "Did both students and teachers take time to reflect on their individual and combined experiences?" as a means to encourage techniques for reflection in design. The reason for asking such a question, and the value of the practices of reflection-in and reflection-on action, provide firm grounds from which to excavate in the process of presenting the Polar Project's highlights, challenges and recommendations for future consideration.

Reflective practice is associated with the work of John Dewey (1938) and Donald Schön (1983) regarding the professional practices of educators. Schön (1983) argues that "society's emphasis on technical rationality has led to an undervaluing of the practical knowledge of action that is central to the work of practitioners" and is what he terms "knowing-in-action" (Schön cited in Mundy 1989, 31). It is for this reason that Schön (1983) promotes reflection-in-action as epistemological of the design process.

Reflection-in-action, according to Çimer et al. $(2013,135)$, "includes moment-to-moment monitoring of action and making immediate adjustments to developments in the situation". We contextualise this definition and understand it by how students tinkered with design ideas, such as in experimenting with technologies to construct an "EKO classroom" - explained later in this article - to develop their designs for the Polar Project. During this tinkering, students were found to adjust unworkable ideas to make them more practical and workable.

Some of these ideas, along with general problems which also arose and their solutions, were expressed in the reflective report and responses to the questionnaires received from the participating students. Reflection-on-action, contrarily, is a more systematic and considered process of deliberation-enabling analysis, and a reconstruction and reframing of processes, in order to plan for future teaching and learning. Further to this, it provides opportunities for collaborative preparation and teaching for projected activities, because it includes both organising and communicating with others (Day 1999; Çimer et al. 2013).

We contextualise and understand this definition in terms of the process we experienced in guiding students during the Polar Project, and in this article, we consolidate accounts of the 
overall experience into considered ideas for the future of such cross-disciplinary and exploratory projects.

During their inception, reflection-in-action and reflection-on-action attracted some criticism as concepts. For example, one counterargument forwarded by Mundy (1989) is how the term reflection-in-action might be problematic, since upon examination, it appears to involve removing oneself from the action in order only to reflect (Court 1988, 143).

Another objection to the use of these frameworks for development in learning is Schön's (1983) distinction between reflection-in-action and reflection-on-action, and how what these terms imply could separate thinking during practice from thinking performed either before or thereafter (Clandinin and Connelly 1986, 32 cited in Mundy 1989).

Although not critiquing the framework, Edwards (2017) builds on it by proposing an additional perspective for reflection and adding the concepts of reflection-before-action and reflection-beyond-action to what is an otherwise somewhat two-dimensional process. According to Edwards $(2017,12)$ the reflection-before-action dimension may assist to "think about situations before entering into practice [...] while reflection-beyond-action [...] enhance[s] self-exploration and awareness, promote[s] lifelong learning, advance[s] practice development and lead[s] to transformative learning."

Although Edwards' contribution to the area is valuable, and since our framework for the project is limited to the two-dimensional ideology already stated, our approach nevertheless compensates for this by taking into account student reflections on the design process as a mechanism to mine knowledge from their experiences for the projected further development of such projects.

For the purposes of the article, we adopt an understanding of reflection as being an enabler of dialogue from a Freirean perspective (Freire 2005, 80). According to Paulo Freire $(2005,80)$, through dialogue, "[t] he teacher is no longer merely the one who teaches, but one who is himself taught in dialogue with the students, who in turn while being taught also teach. They become jointly responsible for a process in which all grow."

For us, Freire's idea promotes a process of democracy and unity in learning where the voice of the student is considered, and their ideas applied. Voice is discussed by Amartya Sen (2005) as significant for "dialogic commitment" (Sen 2005, 35); for "practical impact", and in "the pursuit of equitable and democratic processes" (Sen 2005, 37). Garutsa and Mahlangu $(2014,311)$ acknowledge the importance of the voice of students, particularly in the context of HEIs, and further asserts that it is important to listen to what students say, and also to how it is said.

Reflection as an expression of the student voice was therefore used in assessing the 
outcomes of the Polar Project, and as educators, we endeavour to demonstrate how it assisted in building values and teaching lessons for the further development of projects which the initiating institution regards as international in their scope.

\section{PARTICIPANTS AND POSITIONALITIES IN THE POLAR PROJECT}

The project included undergraduate students from the faculty of Computing and Informatics in the DTC at the Windhoek-based university, and both undergraduate and postgraduate students from DUT's FAD Departments of Fashion and Textiles, Interior Design and Jewellery Design. The HODs for these departments were approached to nominate one student each possessing an interest in innovative design processes, such as 3D printing.

We also nominated two students from our own Fashion and Textiles Department, whom we knew held a similar aptitude. Due to time constraints, DUT's Fine Arts and Graphic Design Departments were not approached to nominate any of their students sharing this area of interest. In Windhoek, an open call was extended by the university's DTC for students from all faculties to apply for the opportunity of participating in the project. Applicants were shortlisted, then invited for interviews, and finally narrowed down to include only those who were successful.

As mentors, facilitators and researchers, we were sensitive of our multiple and unstable positionalities in the project, and to the concomitant blurring of insider-outsider boundaries which this implied (Sultana 2007). As mentors, we were on the inside of the project, which included, amongst other things, experimenting with students in activities such as embroidery with conductive thread, the design and building of a design model, the setting up of FAD's upcoming Digifest exhibits, and also participation in meetings and discussions with students. Digifest is an annual FAD festival which encourages student and staff to incorporate digital media for and in their creative outputs, and the creative outputs for the Polar Project were therefore also intended to be showcased at this event.

In our capacities as facilitators and researchers we were, to a degree, considered to be outsiders by the students. Although, as facilitators, we allowed students freedom of design, responsibility for the independent sourcing of materials, and the performance of all administrative tasks, amongst other things, as researchers we were also seen to be documenting the process by analysing student presentations, reports and questionnaire responses concerning their reflection-in-action for the project and photographing the project's activities for data collection.

As mentors and facilitators, we completed reports on student participation, and the project's progress, which can be interpreted as being part of the reflection-in-action process. These are, however, not analysed within the scope of this article. 


\section{ITERATIONS FOR PROTOTYPE DEVELOPMENT: STUDENT REFLECTIONS-IN- ACTION IN CO-DESIGN}

The students from both DUT and the DTC made use of Participatory Design (PD) methodology (Spinuzzi 2005) to work as a team in designing and prototyping a solution for their identified project.

Also termed as co-design (Kleinsmann et al. 2007; Sanders and Stappers 2008; Kensing and Greenbaum 2012; Pedersen 2016; Mchunu and Berman 2018), and co-creation (Prahalad and Ramaswamy 2004; Seppä and Tanev 2011; Martinez-Canãs, Ruiz-Palomino and BlázquezResino 2016), PD is defined by Spinuzzi $(2005,166)$ as being "constructivist in that it sees knowledge-making as occurring through interaction among people, practices and artefacts".

Marc Steen (2013) describes PD as collaborative design-thinking, in which "diverse people jointly explore and define a problem and jointly develop and evaluate solutions. It is a process in which participants are able to express and share their experiences, to discuss and negotiate their roles and interests, and to jointly bring about change" (Steen 2013, 27). PD is believed to be a branch of action research (Spinuzzi 2005), and therefore entails action, followed by reflection on the design actions performed.

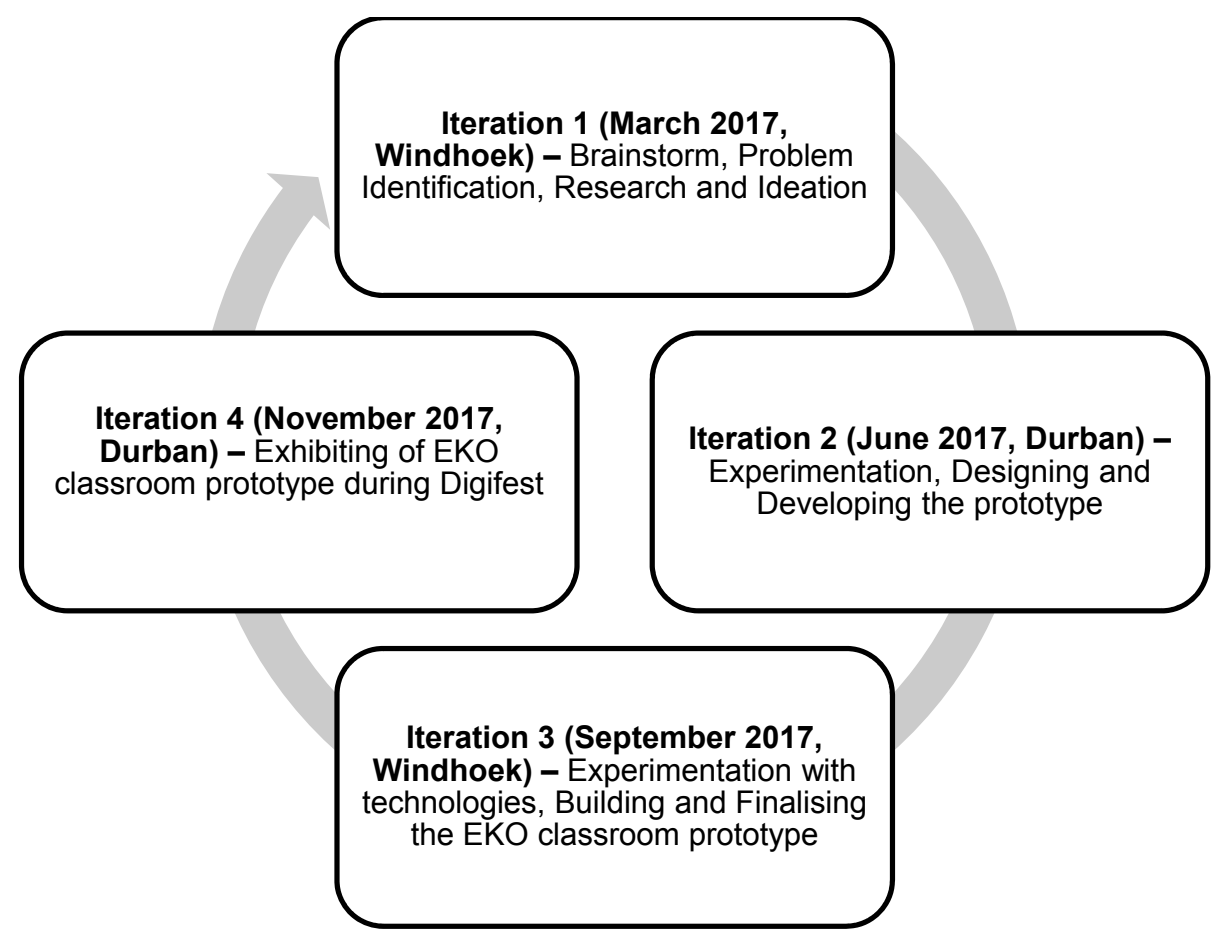

Cycle Graphic 1: The iterations the team underwent to design the EKO classroom; in between iterations, the group continued to work as a virtual team

Similarly, the Polar Project group treated each trip to the two venues where activities were hosted as iterations with planned activities (Cycle Graphic 1). Each iteration ended with student 
reflection concerning highlights, challenges and recommendations for the next iteration.

The reflections at the end of each iteration can be perceived as reflection-on-action, conducted to inform activities for the next iteration; however, for this article we view these as reflection-in-action, because each period of reflection led up to the ultimate goal of designing a prototype for FAD's Digifest.

\section{Iterations 1-3 (March - September 2017)}

After an intense brainstorming and ideation session, the students came up with three concepts which addressed social challenges that they had identified as existing in both their cities of origin. These were, firstly, a mobile structure designed for entrepreneurs within urban marketplaces, and secondly, an interactive sensory tripod for the physically-challenged, in particular the visually impaired (Figure 1 and 2).

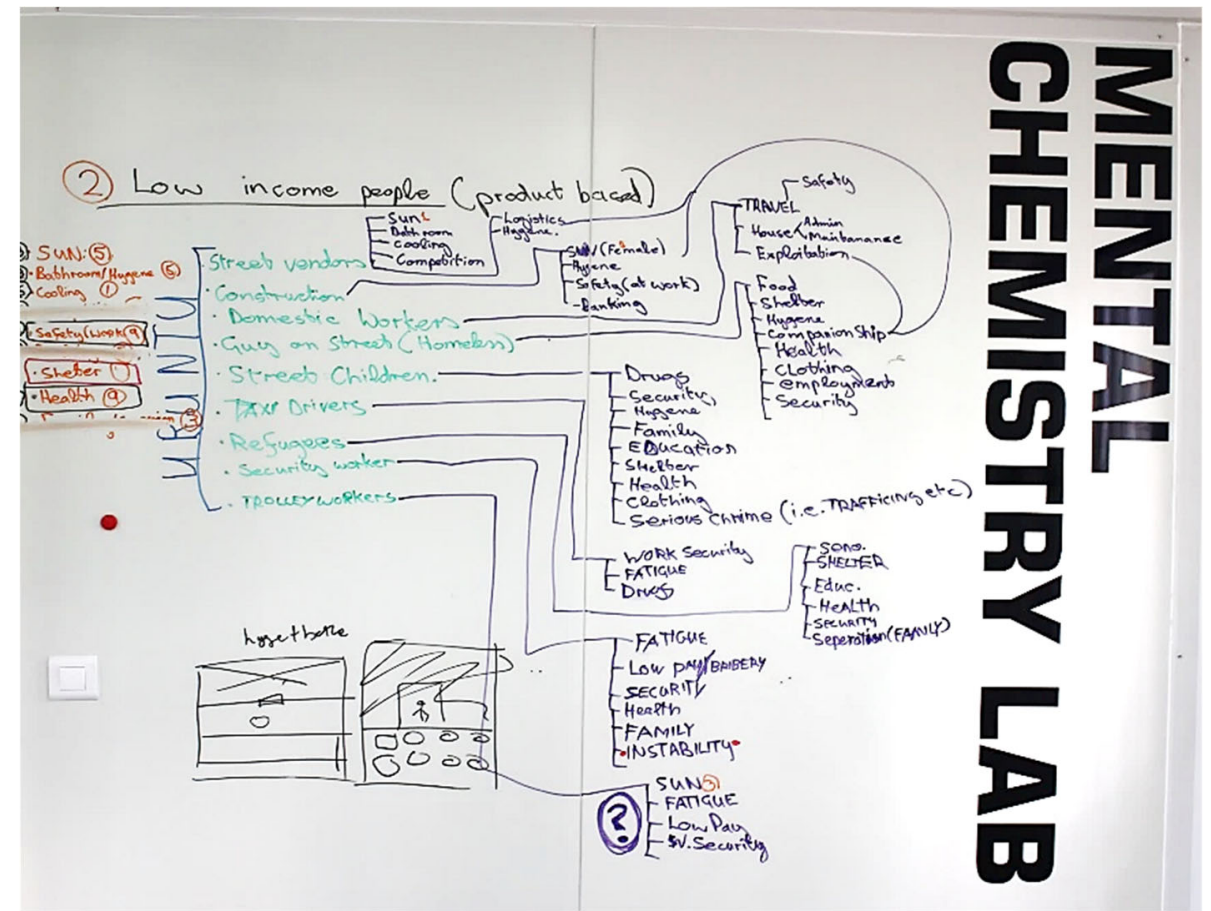

Figure 1: Ideation of a social challenge for the project (Photo: Khaya Mchunu)

The third and winning idea was what became termed the "EKO classroom". Students used knowledge obtained from their respective fields to develop a plan for designing and constructing an innovative product, which they called a "learning capsule", and subsequently dubbed the "EKO classroom". The word "EKO" was chosen by the students themselves, and derives from the Yoruba word "eko", which, loosely translated, means "academic", "education", "learning", or "to educate".

After looking at the various options, the team settled on the name "EKO classroom", 
which they considered the most appealing and memorable title for the development. The classroom was designed to introduce learners at senior-primary level to coding and electronics through their curriculum. Prototyping the EKO classroom concept occurred during a set of iterations, including face-to-face interactions with one another, with students spending a maximum of one week at each venue, and working directly on the project during these on-site visits.

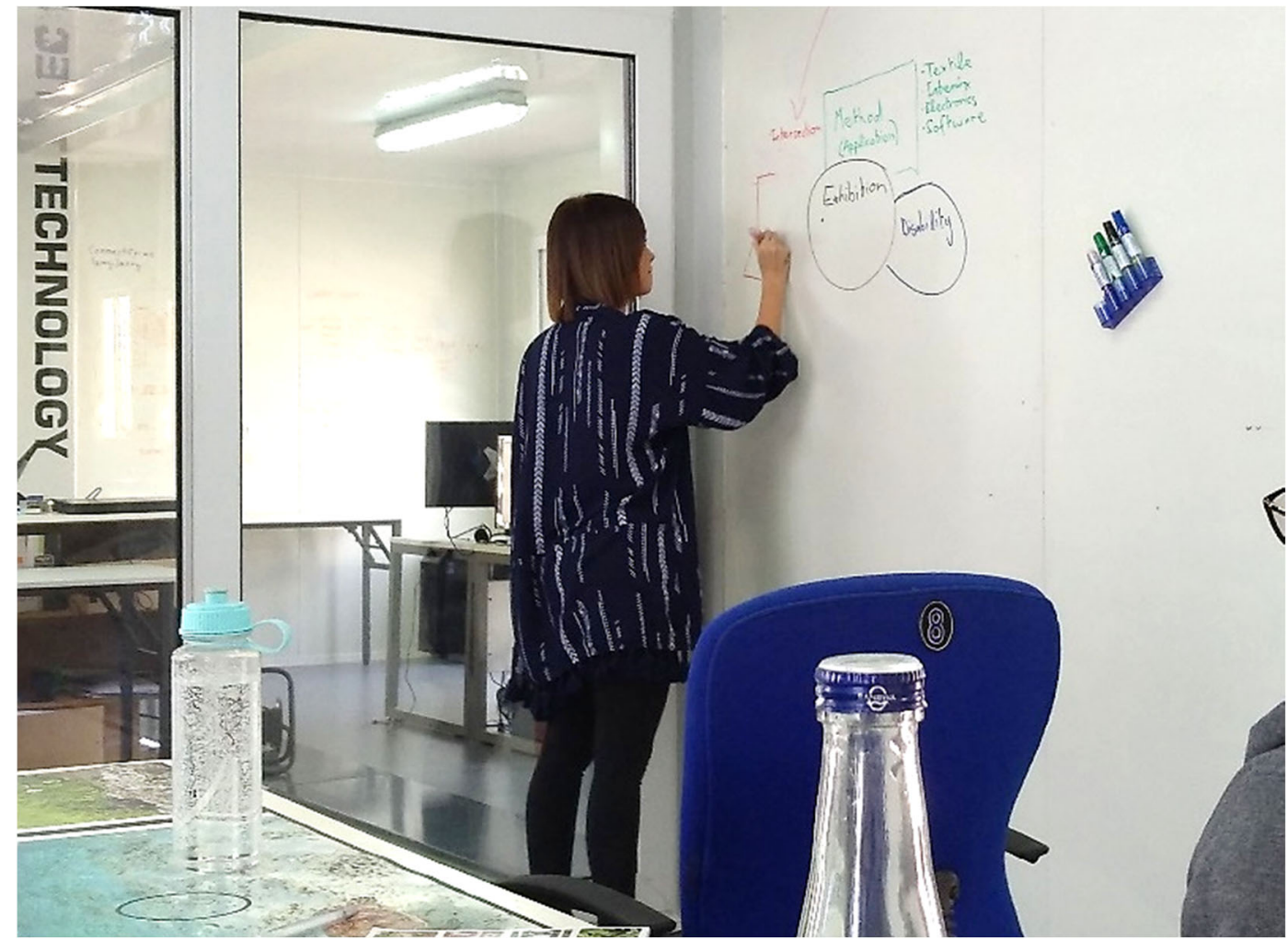

Figure 2: Student writing down idea notes (Photo: Khaya Mchunu)

The periods between these visits required the group to operate remotely as a "virtual team", defined by Jordan and Adams $(2016,185)$ as a team which is "geographically dispersed, such that a significant amount of work [is] mediated by technology-based communication" (Jordan and Adams 2016, 185). In these virtual cases, the team made use of other forms of electronic and online communication, including Trello-based project management, WhatsApp groups, Skype meetings, and email exchanges. The virtual cases were also more democratised and consistent with the Freirean idea of dialogue in the sense that, as mentors, we joined in the meetings and adding in our own ideas.

The design of the EKO classroom encountered some resistance during its research phase, which rapidly demotivated the team, and required some serious reflection-in-action to restore their resilience. One major challenge to the co-design process was the excessive bureaucracy 
the team encountered in being allowed to engage with a government school.

The process for this included submitting a proposal to the research sector of the South African Department of Education, and then awaiting approval from them, since only when this was granted could the team approach a school which might be interested in participating in the project. The application to the Department of Education was completed and submitted in May 2017, but no response was received from them until November 2017, during the Digifest event itself.

Another obstacle arose when a primary school principal decided to attend the team's presentation of the project's "learning capsule" concept. The principal, quite justifiably, questioned the students critically, and also challenged the idea that a team of students without any teaching qualifications should be designing such a device intended for the education sector. These frustrations were "voiced" in student reflections at the end of this iteration. The student reflections worked as enablers of dialogue and became helpful to us as mentors together with our Namibian counterpart to find ways to renew the energy we had in the initial stages of the project.

Pedersen $(2016,173)$ states, "creating and sustaining a co-design practice is an ongoing activity throughout a project". Likewise, with the Polar Project, in order to sustain the design process and regain their positivity in the face of all opposition, we asked the group to rely on their memories as previous school-learners and take initiative as a team in designing their EKO classroom, based on how they envisioned a classroom would exist in the future. During a later iteration cycle in Windhoek, the Namibian mentor organised for the team to visit a Montessori school to perform the additional research necessary to continue with the project.

We would like to emphasise that the students did not overlook, or reduce their merit as a team, by dismissing the critique extended by the primary-school principal, but instead remained inspired to look into alternative approaches. After reflecting on this problem, the students changed their idea of introducing coding and electronics through the school curriculum to that of introducing coding and electronics through the study of technological innovations.

\section{Iteration 4 (November 2017)}

The final EKO classroom design exhibited at Digifest comprised many African-inspired elements. The students designed a collapsible structure, which allowed for maximum mobility of the device, so that, as they imagined, they could travel to various schools and introduce coding and electronics using this "designed space".

The basic shape adopted was a modern interpretation of the traditional African rondavel design, which is a traditional grass-roofed thatch hut. During the Namibian group's leg of their 
Durban visit in June, the team visited a museum focusing on African traditional art, and it was during this trip that they learned of a traditional form of writing employing graphics which originated with the Zulu people of KwaZulu-Natal.

The museum orator explained how these graphics, which were typically used on Zulu garments, held a dual purpose; these being for reasons of aesthetics, and also as a form of symbolic writing. The team drew inspiration from this and used the computer-aided design (CAD) software, Adobe Illustrator, to create their own African-inspired geometric shapes for the exterior of the EKO classroom prototype, with this actually taking place during Iteration 3. Saki Mafundikwa's (2004) research on African alphabetical systems was referenced as a guide by the students, and the graphics created were intended as a series of symbols comprising a poem written in English by the students about unity and hope in Africa.

The centre of the interior space for the EKO classroom contained a stylised, laser-cut Baobab, which is a tree native to many parts of Southern Africa (Figure 3 and 4). Besides its use for aesthetic purposes, the Baobab was also designed to function as a storage area for the electronics, batteries and other materials to be used in the "virtual classroom". According to the students, the tree could also contain a drawer in which learning materials might be stored, and which included a set of handcuffs.

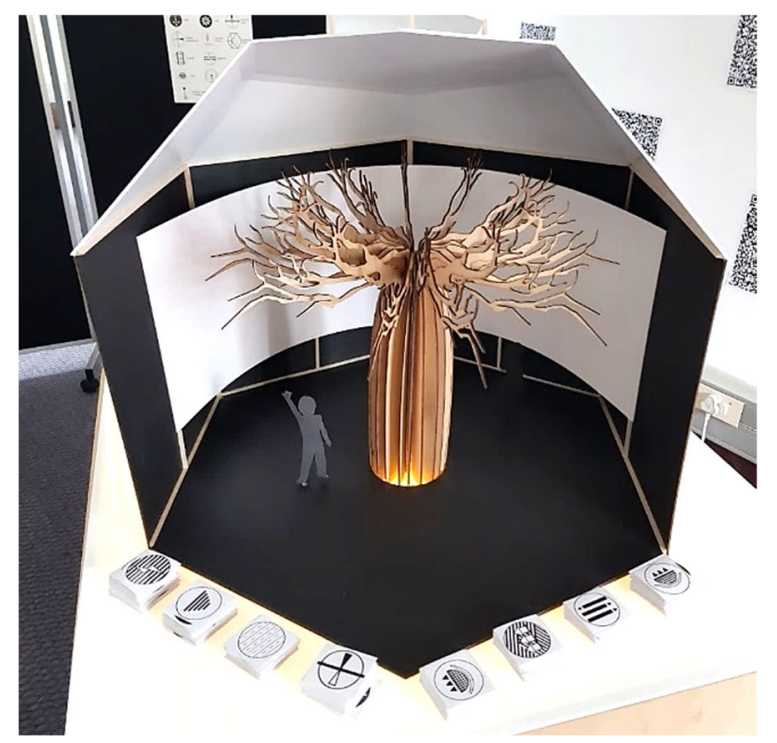

Figure 3: EKO classroom exhibited during the FAD's Digifest (Photo: K. Gounder)

The set of handcuffs was designed and manufactured in two ways, namely: as a 3D-printed version produced by the participating Jewellery Design student, and also in the form of a moulded-and-cast version, created by the co-founder of the DTC in Windhoek, which occurred during Iteration 3, and also in the "virtual team" phase intervening. 
According to the concept's design plan, upon entering the EKO classroom, an avatar would appear to the learner on the space's internal wall, which was designed as a curve to allow for the projection of an avatar, which, for prototype-purposes, was rigged on top of the Baobab tree. The learner would be prompted to customise the avatar by changing its hair and clothes from the selection of design prints supplied for the prototype in the space's item repository. Some of the textile prints used for these elements were designed and produced by the participating fashion students.

The plan for the interior of the space was to develop the avatar to function as a facilitator in the EKO classroom, guiding the school learner through physical and virtual gamification activities, and interacted with via hand gestures and motion-detection equipment operated using a handcuff worn by the learner. A Microsoft Kinect camera, which could be fitted on a track running along the middle of the inside wall of the classroom, was located at a height also considered convenient for the average child.

This Kinect system would be used to record the child's hand gestures through motiondetection technology. A Unity game engine was the software selected by the Windhoek students, during the "virtual" phase following Iteration 3, as the software for controlling the avatar's functionality within the space, and although the motion-detection application for the avatar was not fully functional during Digifest, the customising function for the avatar was.

The completed EKO classroom prototype, along with supporting presentation boards providing full details of the project, and also QR codes allowing access to additional digital content, was exhibited during Digifest in November 2017.

The prototype is the result of many processes of ideation and research undertaken by the students involved in the project, including experimentation with innovative tools, such as Arduino single-board micro-controllers, embroidery techniques using conductive thread to create circuits, an electronic sensor-screen printed with electric paint, the use of Raspberry Pi learning computers, laser-cutting and engraving, and also the performing of more traditional research, such as museum visits.

\section{VALUES AND LEARNINGS GENERATED FROM STUDENT REFLECTION-IN- ACTION: OUR REFLECTION-ON-ACTION}

The Polar Project was an innovative and multi-disciplinary initiative which was exploratory in nature and involved students from diverse fields with the objective of developing and strengthening them in the process of becoming global citizens.

In discovering the values and lessons promoted by the Polar Project, we analysed both the reports completed by students during their project participation, and also their responses to the 
final reflective questionnaire completed at the project's conclusion. From this analysis, we identified patterns in their responses, in order to formulate the themes which indicated the values and lessons learned by the students in taking part in the project, from their unique student perspective.

Although students were provided with journals in which to document their progress during the project, these were generally unsuccessful as records of this, since students used these journals for drafting their design ideas instead. The student questionnaire responses, however, provided us with a useful guide in establishing how we might improve on our practice as mentors, facilitators and researchers for future projects of a similar nature.

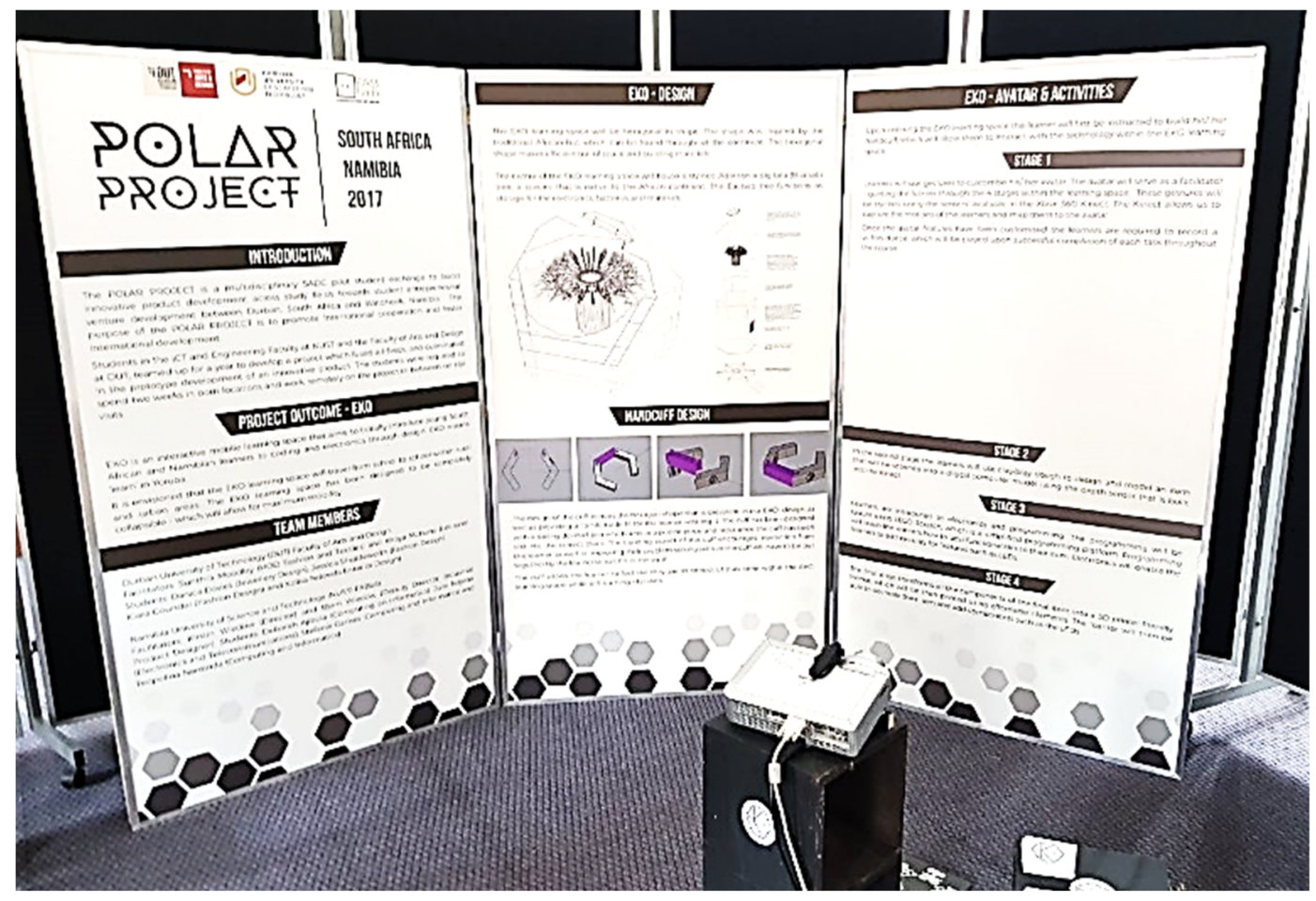

Figure 4: Polar Project presentation at FAD's Digifest (Photo: K. Gounder)

Some of the significant themes identified from the reports and questionnaires include those values and learnings regarding cross-cultural exchanges, collaboration and group communication, acquired by the students during their participation in the project.

\section{CROSS-CULTURAL EXCHANGES}

One of the objectives of the Polar Project was to provide students with an opportunity for crosscultural exchanges and experiences. All of the DUT students who participated in the project declared that its highlight for them was in travelling to another country, with responses to the question posed to the students regarding what they considered to be the project's highlights 
provoking such comments as: "[e]xperiencing a different culture", and, "[t]he exchange program is a good idea, and it is exciting to learn about new cultures and subjects".

A response from another student that "[v]isiting the country of Namibia, I thought I would have some sort of culture shock, or unfamiliar experiences; however, I came to learn that Namibia is very much like South Africa in most respects [...] The food was [similar], if not the same, as South African cuisine, and thus I felt quite at home" suggests that they learned much about the similarities which exist between their home country and Namibia.

These comments indicate how student participation in the Polar Project contributed to its objective of enabling their growth as global citizens, as stipulated in the project's SFA. Noteworthy is that one of our HEI's aim is to develop both staff and students as global citizens through such cross-cultural partnerships; therefore, whilst our students obtained much knowledge of other cultures during the project, we as mentors and facilitators underwent a similar journey.

The trip to Namibia in support of the project was our first, and from the perspective of cross-cultural exchanges, it was rewarding to be jointly involved with our Namibian counterparts in the process of mentoring and guiding both our own students, and also students from another country, along with those also belonging to different disciplines from our own. This instance also indicates that mentoring collaboratively, works in a disciplinarily diverse context.

\section{MULTIPLE APPRECIATIONS OF COLLABORATION}

Another significant theme which emerged from the project's report and questionnaire responses is that of the rewards obtained from collaboration when viewed from multiple perspectives by the students. These perspectives include those of: (1) inter-institutional collaboration; (2) crossdisciplinary collaboration; and (3) collaboration as a conduit for transcendent understanding of disciplinary limits.

We understand inter-institutional collaboration as a concept for applied learning, used when different organisations work together towards a shared objective (Dörner et al. 2011; King et al. 2013). Working with both an outside organisation (FAD and the DTC), and within the organisation (DUT's Departments of Fashion and Textiles, Interior Design and Jewellery Design), the inter-institutional collaboration during the Polar Project, can be perceived as having many far-reaching implications.

The DUT Faculty of the Arts and Design comprises nine departments, spread out over four campuses. Collaboration of the nature imbued in the Polar Project is generally almost impossible to achieve at any given time, due to the perceived distances between them. This 
project, with its weekly meetings, which brought participants from the participating departments involved together, therefore has special meaning for the DUT team in particular.

Remarks from students, such as " $\mathrm{t}]$ he Polar project made the Durban team a lot stronger as individuals, as we learned to stand by each other, and push through every block without giving up, but rather learning and pushing harder", "[w]orking with the South African designers has been an enjoyable experience - the four of us worked extremely well as a team; although we come from different design disciplines, we all shared the same vision for the outcome of this project", and finally, "I think that there should be more collaborations in the future between different departments, disciplines, universities and countries, as I think that, as people of different expertise come together, then different opportunities present themselves that would not have been chartered if the collaboration had not taken place", all indicate an appreciation of the value of collaboration occurring within the faculty which serves to endorse the culture of togetherness inherent across our respective departments. Although the initial agenda was to endorse collaboration with an outside organisation, this project indicates that internal collaboration is desirable.

The cross-disciplinary collaboration with students from other disciplines - in this case engineering and software design students from Windhoek - was also repeatedly mentioned by the DUT students as a project highlight, with comments such as: "[i]t was interesting", and "fascinating" prevalent. Another comment was "[i]t was interesting to interact with a group that was not from a creative discipline and experience their thought patterns and specialities in technology; something we hardly get to experience first-hand (coding, programming, websites etc.)".

One student went so far as to use metaphorical terms to describe working at the DTC with the following words: "The [centre] where we met and brainstormed is a chocolate factory for chocolate lovers". The student continued by saying that "[o]ne of my favourite aspects of the Polar Project is the cross-disciplinary collaboration; the cross-pollination promises an opportunity that, within each person's individual discipline, they have the prospect to contribute something new and innovative towards pushing their industry forward".

The student's comparison proved significant and provided the impetus for comparing the students' experience on the Polar Project to Roald Dahl's tale of Charlie and the Chocolate Factory, since this recognition of the value of the cross-disciplinary collaboration entered into via the project also indicates an understanding by the students that their own disciplinary limits were transcended through their project experiences.

Comments alluding to this were made by two of the project's students when interviewed by Namibian television crew members: "[b]eing part of the Polar Project has allowed me to 
grow as a person, and look outside myself, and specifically outside of my discipline; and [...] being in the Polar Project I realised that my discipline [...] is not only for interiors, it can have multiple applications by the collaboration of different disciplines".

Another student shared these sentiments regarding the project, in stating that: "[s]o far the collaboration process with the [institution's] and students from [the DTC] has been both interesting and exciting; working with a discipline I am not familiar with has brought a new interest to my own studies, and the way I have been looking at design".

Another highlight of the Polar Project remarked on by the DUT students was that of the workshops on digital and sensory technologies conducted during the project's early stages. These workshops were described in overwhelmingly positive terms, with many of the students using expressions such as "endless opportunities" and "ideas made possible" in describing their experiences with the technologies presented.

The notions of "endless opportunities" and "ideas made possible" were taken even further by one student, who encountered a hoodie embedded with a digital musical keyboard. The student verbalised the inspiration and ideas which encountering the hoodie had sparked for them in stating: "One of the students was working on a hoodie that had a keyboard-type contraption on it, whereby the individual could play and compose music on the hoodie. That very same technology could be used to help autistic children, [as] well as elders with dementia. The very same technology could be made on a larger scale for retirement homes with Alzheimer's and dementia suffers as part of the therapy. Additionally, in a children's hospital it could have profound impact of the rate of recovery of the children."

Although the ideas of this student were not explored further, here we make the point that there is both a positive impact and value in exposing design students to centres for innovation such as the Windhoek-based DTC. Furthermore, their exposure to unfamiliar technologies presented opportunities for both single- and double-loop learning experiences for the participating design students.

It became evident thus, that collaboration has a nuanced purpose and definition in the case of the Polar Project. As stated earlier within collaboration, there is an understanding of its benefit in inter-institutional affairs, its rewards in a cross-disciplinary perspective and how as a practice, collaboration is a conduit that helps to transcendent understandings about disciplinary limits.

\section{COMMUNICATION AND MISCOMMUNICATION IN CROSS-DISCIPLINARY GROUPS}

Jordan and Adams $(2016,187)$ purport that effective communication over distances presents a 
problem, and that this "is also likely to be more challenging for virtual cross-disciplinary teams as compared with virtual disciplinary teams". Miscommunication by the DUT students with their Namibian counterparts in the co-design process was perceived as a major challenge by many of the DUT students, because, according to one student's response, "[t]here [were] also many times where miscommunication slowed our project down", and "[c]ommunicating over distance has been difficult".

As a measure intended to mitigate this challenge, a Trello account was established to which posts were made, thought processes were added, and links to websites for design inspiration were attached. The DUT students considered Trello difficult to use, which led them to starting of a WhatsApp group, which they considered a more familiar and user-friendly platform for use by team members instead.

Emails were also exchanged in order to circulate briefs for tasks to be accomplished between iterations, and in preparation for the next, with these briefs being utilised as a mechanism for assigning responsibilities to each team and being sent to both the DUT and Namibian teams.

With regards to these briefs, one student stated that "[b]riefs were also altered without our knowledge, which proved tricky when we arrived, as they had developed work we did not know about. In the future, we should create a concrete brief which has been well thought-out before the project commences, as re-discussing briefs and coming to new conclusions took up valuable time."

We gather this comment may have been made in response to the process in which the Namibian team preferred a domed shape for the EKO classroom, while the DUT group preferred a hexagonal shape. While some students may have thought this instance marred by miscommunication, a subsequent incident occurred which proves to the contrary.

For their final visit to Namibia, the DUT students built a miniature model of the EKO classroom, while unbeknownst to them the Namibian team had gone ahead and built a full-size version using their own initiative. Despite the fact that both teams made use of different materials for their respective structures, the idea embodied by both models, based on prior communication, or rather miscommunication as they perceived it, was identical.

What can be deduced from this incident is that miscommunication between crossdisciplinary groups, in this example, was not necessarily true miscommunication, because the student ideas and thought-processes which went into constructing each structure were, to a great extent, essentially in harmony.

A perplexing aspect of this example, however, is the different views concerning the shape chosen for the structure by each team, where the Namibian team used a dome, while the DUT 
students selected a hexagon. The Namibian team considered that their shape allowed for greater facility in projecting the avatar on the interior wall of the structure, while the DUT team selected a hexagonal shape for their design in order to aid in building a more easily-collapsible structure.

This example indicates an instance of "difference in disciplinary language and paradigms between team members", as expressed by Jordan and Adams $(2016,187)$. The tasks executed, with the completed structures both fulfilling the aim set for the project, remained, despite a slight disparity in vision, fundamentally in unison.

\section{PRACTICAL IMPLICATIONS OF EXTRACURRICULAR PROJECTS LIKE THE POLAR PROJECT}

Participation in the Polar Project was an initiative intended to promote extracurricular activities undertaken by the students. In keeping with this, one of the students, in agreement with some of the others, declared that "[w]orking on this project, in addition to my work and Master's commitments, has been challenging. The short time-frame of the Polar Project put added pressure on all the students involved to achieve the project goals."

We were aware that participation in the project could compromise some of the students' academic progress. Because of this, it is suggested that student engagement in such projects in future might be conducted as part of their research projects at BTech and/or Master's level, since in this way students can then focus exclusively on the project, with research reports being presented by students as part of their required qualification outcomes. Such an approach would, however, necessitate thorough planning in the form of funding, support and research supervision for these projects.

As a result of the multidisciplinary approach which such projects require, they would also benefit from being stipulated as exploratory in nature, and including extended disciplinary parameters, including ontological, epistemological and methodological approaches not fixed within any one discipline. For the purposes of the discipline of design, this research could be conducted in support of the constantly-growing sub-field of design for social innovation.

This proposition takes into consideration the following comment from another student: "I think that, when engaging on a collaboration, there should be a workshop taken before the teams engage, where the participants are taught on collaboration management, like fostering good personal relationships, understanding diverse cultures, having written agreements, sticking to roles assigned, leadership elected, and vision of the team focusing on the big picture, careful planning, and the proper use of technology".

These kinds of workshops could contribute to preparatory measures in support of students participating in multidisciplinary projects such as the Polar Project, although capacities would 
also need to be put into place in support of the academics who supervise such projects.

We thus concur with Burch et al. $(2016,234)$, who propose that "[w]hile such programmes do have the potential to equip graduates with the required knowledge and competence to achieve [interdisciplinary programmes], the academic project can only be sustained by the appropriate training of teachers responsible for providing this type of education". While, through the reflection, the student gave recommendations for logistics of the project, at the most basic level, the instance also shows how a student experiential reflection presents an opportunity to refine an internationalised university project such as the Polar Project - one that is led by students

\section{CONCLUSION}

In this article, we raise the question: "What values and lessons can be gained through co-design in a culturally and disciplinarily diverse cross-university student project?" The question is used as the basis for reflection-on-action regarding student participation in the Polar Project, in which reports, and questionnaires were provided as enabling tools for them to perform their own reflection-in-action.

Student reflection-in-action was thus used as a mechanism which allowed us, as mentors, facilitators and researchers, to reflect-on-action. The aim of applying Schön's (1983) framework in this manner was to promote reflection-in-action as an approach which allowed us to hear the voice of the students, and also spark dialogic processes as our faculty embarks on its course of internationalisation.

In introducing this article, we cite an excerpt from Roald Dahl's well-known book Charlie and the Chocolate Factory, and in concluding our review, we provide an extended selection from the same work, as given below:

"But I haven't yet told you about the one awful thing that tortured little Charlie, the lover of chocolate, more than anything else. This thing, for him, was far, far worse than seeing slabs of chocolate in the shop windows or watching other children munching bars of creamy chocolate right in front of him. It was the most terrible torturing thing you could imagine, and it was this: In the town itself, actually within sight of the house in which Charlie lived, there was an ENORMOUS CHOCOLATE FACTORY! Just imagine that! And it wasn't simply an ordinary enormous chocolate factory, either. It was the largest and most famous in the whole world! It was WONKA'S FACTORY, owned by a man called Mr Willy Wonka, the greatest inventor and maker of chocolates that there has ever been. And what a tremendous, marvellous place it was! It had huge iron gates leading into it, and a high wall surrounding it, and smoke belching from its chimneys, and strange whizzing sounds coming from deep inside it. And outside the walls, for half a mile around in every direction, the air was scented with the heavy rich smell of melting chocolate! Twice a day, on his way to and from school, little Charlie Bucket had to walk right past the gates of the factory. And every time he went by, he would begin to walk very, very slowly, 
and he would hold his nose high in the air and take long deep sniffs of the gorgeous chocolatey smell all around him. Oh, how he loved that smell! And oh, how he wished he could go inside the factory and see what it was like!"

This excerpt returns us to the symbolic and picturesque comparison of the DTC with a "chocolate factory for chocolate lovers", as expressed by one DUT student.

An analysis of the themes, motifs and symbols observed in Dahl's book suggest that the chocolate factory also represents the idea that things cannot be fairly judged using an exclusively external perspective. Hence, a structure may appear enormous from the outside, but its true glories may lie beneath the ground, where they cannot be seen without taking a closer look.

If we view our students metaphorically, as "Charlies", and their participation in the Polar Project as their symbolic entry into a chocolate factory, which represents a space enabling them to successfully accomplish co-design and contribute to the internationalising agenda, some genuine treasures may indeed have been obtained by them from the project's DUT version of Charlie's factory.

Reflections as an enabler of dialogue, a method through which we hear student voice but also learn from this voice demonstrates that cross-cultural exchange is an enabler allowing students to grow into global citizens, an appreciation of collaboration at both inter-institutional and cross-disciplinary levels, and the meta-view of collaboration as a conduit for transcending disciplinary limits, are all here identified as being amongst the project's practical applications. Demonstrating our understanding of the internationalisation of higher education as a process of intersecting education and teamwork in multiple disciplines. These can all be regarded as the values and lessons which we take with us in embarking on yet another cycle of the Polar Project in the anticipated future.

\section{ACKNOWLEDGEMENTS AND DEDICATION}

This project was funded by the Teacher Development Grant. We would like to acknowledge the support of DUT's FAD Research Officer in organising the writing retreat which saw this article produced, and of all our colleagues who commented on its drafts. We dedicate this article to the DUT students who participated in the Polar Project, and to the students and co-founders of the Design and Technology Centre at the participating university in Windhoek.

\section{REFERENCES}

Bannon, L. J. and P. Ehn. 2012. Design matters in participatory design. In Routledge International Handbook of Participatory Design, ed. J. Simonsen and T. Robertson, 37-63. London: Routledge. 
Burch, V. C., J. Lewis, U. Subramaney, A. Katurura, G. Quinot, S. Singh and R. Dhunpath. 2016. Innovative towards a conceptual framework for interdisciplinary teaching and learning dialogues in higher education. Alternation 23(1): 233-264. http://alternation.ukzn.ac.za/Files/docs/ 23.1/23,1.pdf

Çimer, A., S. O. Çimer and G. Vekli. S 2013. How does reflection help teachers to become effective teachers?" International Journal of Educational Research 1(4): 132-149. http://ijsse.com/ijer/ sites/default/files/papers/2013/v1i4/Paper-1.pdf

Clandinin, D. J. and F. M. Connelly. 1986. The reflective practitioner and practitioners' narrative unities. Canadian Journal of Education 11(2): 184-198. http://www.jstor.org/stable/pdf/1494806.pdf

Coates, H, P. Kelly, R. Naylor and V. Borden. 2016. "Innovative approaches for enhancing the 21st Century student experience. Alternation 23(1): 62-89. http://alternation.ukzn.ac.za/Files/docs/ 23.1/04\%20Coates\%20F.pdf

Court, D. 1988. Reflection-in-action: Some definitional problems. In Reflection in teacher education, ed. P. Grimmett and G. Erickson, 143-146. Vancouver, BC: Pacific Education Press, New York: Teachers College Press.

Dahl, R. 1964. Charlie and the chocolate factory. New York: Alfred A. Knopf Inc.

Day, C. 1999. Developing teachers: The challenge of lifelong learning. London: Falmer Press.

Dewey, J. 1938. Experience and education. New York: Touchstone.

Dörner, N., F. Morhart, O. Gassmann and T. Tomczak. 2011. Inter-institutional collaboration for new integrative teaching programs. On the Horizon 19(3): 217-225. https://doi.org/10.1108/ 10748121111163922

Edwards, S. 2017. Reflecting differently. New dimensions: Reflection-before-action and reflectionbeyond-action. International Practice Development Journal 7(1): 1-14. https://doi.org/ 10.19043/ipdj.71.002

Freire, P. 2005. Pedagogy of the oppressed: $30^{\text {th }}$ Anniversary Edition. New York: Continuum.

Garutsa, T.C. and P. M. Mahlangu. 2014. "Using transdisciplinarity in the university: Giving a voice to the voiceless in the grounding program at Fort Hare, TD." The Journal for Transdisciplinary Research in Southern Africa 10(3): 310-322. https://dspace.nwu.ac.za/bitstream/handle/10394/ 12876/02a\%20Garutsi\%20\%26\%20Mahlangu.pdf?sequence=1\&isAllowed=y

Hagenmeier, C. C. A., A. Lansink and G. Vukor-Quarshie. 2017. "Internationalisation and African intellectual métissage: Capacity-enhancement through higher education in Africa." South African Journal of Higher Education 31(1): 81-103. http://dx.doi.org/10.20853/31-1-821

Haigh, M. J. 2002. Internationalisation of the curriculum: Designing inclusive education for a small world. Journal of Geography in Higher Education 26(1): 49-66.

Higgins, C. 2011. The good life of teaching: An ethic of professional practice. Oxford: Wiley-Blackwell

Jordan, S. and R. Adams. 2016. Perceptions of success in virtual cross-disciplinary design teams in large multinational corporations. CoDesign: International Journal of CoCreation in Design and the Arts 12(3): 185-203. http://dx.doi.org/10.1080/15710882.2016.1146303

Kensing, F. and J. Greenbaum. 2012. "Heritage: Having a say." In Routledge international handbook of participatory design, ed. J. Simonsen and T. Robertson, 21-36. London: Routledge.

King, S., J. Drummond, E. Hughes, S. Bookhalter, D. Huffman and D. Ansell. 2013. An interinstitutional collaboration: Transforming education through interprofessional simulations. Journal of Interprofessional Care 27(5): 429-431. http://www.tandfonline.com/doi/full/10.3109/ 13561820.2013.791260?scroll=top\&needAccess $=$ true

Kleinsmann, M. S., A. C. Valkenburg and J. A. Buijs. 2007. Why do(n't) actors in collaborative design understand each other? An empirical study towards a better understanding of collaborative design. CoDesign: International Journal of CoCreation in Design and the Arts 3(1): 59-73. https://doi.org/10.1080/15710880601170875

Mafundikwa, S. 2004. Afrikan Alphabets: The story of writing in Afrika. New York: Mark Batty 
Publisher

Martinez-Canãs, R., P. Ruiz-Palomino and J. J. Blázquez-Resino. 2016. Consumer participation in CoCreation: An enlightening model of causes and effects based on ethical values and transcendent motives. Frontiers in Psychology 7(793): 1-17. http://doi:10.3389/fpsyg.2016.00793

Mchunu, K. and K. Berman. 2018. Arts-based methods as tools for co-design in a South African community-based design co-operative. Cubic Journal 1: 34-49.

Mundy, H. 1989. "Reflection-in-action and Reflection-on-action." Education and Culture: The Journal of the John Dewey Society 9(1): 31-41. https://docs.lib.purdue.edu/eandc/vol09/iss1/art4/

Pedersen, J. 2016. "War and peace in CoDesign." CoDesign: International Journal of CoCreation in Design and the Arts 12(3): 171-184. http://dx.doi.org/10.1080/15710882.2015.1112813

Prahalad, C. K. and V. Ramaswamy. 2004. "Co-creating unique value with customers." Strategy and Leadership 32(3): 4-9. http://doi.org/10.1108/10878570410699249

Quayle, M. and D. Paterson. 1989. "Techniques for encouraging reflection in design." Journal of Architectural Education 42(2): 30-42. http://www.jstor.org/stable/1425089

Reich, S. M. and J. A. Reich. 2006. Cultural competence in interdisciplinary collaborations: A method for respecting diversity in research partnerships. American Journal of Community Psychology 38(1-2): 51-62. https://www.ncbi.nih.gov/pubmed/16807789

Robson, S. 2011. Internationalisation: A transformative agenda for higher education? Teachers and Teaching 17(6): 619-630.

Sanders, E. B. N. and P. J. Stappers. 2008. Co-creation and the new landscapes of design. CoDesign: International Journal of CoCreation in Design and the Arts 4(1): 5-18. http://www.tandf online.com/doi/pdf/10.1080/15710880701875068?needAccess $=$ true

Schön, D. A. 1983. The reflective practitioner: How professionals think in action. New York: Basic Books.

Schön, D. A. 1987. Educating the reflective practitioner: Toward a new design for teaching and learning in the professions. London: Jossey-Bass Publishers.

Sen, A. 2005. The argumentative Indian: Writings on Indian history, culture and identity. New York: Farrar, Straus and Giroux.

Seppä, M. and S. Tanev. 2011. The future of CoCreation. Technology Innovation Management Review 6-12. https://jyx.jyu.fi/dspace/bitstream/handle/123456789/40172/futureofcocreation.pdf? sequence $=1$

Spinuzzi, C. 2005. The methodology of participatory design. Technical Communication 52(2): 163174. www.jstor.org/stable/43089196

Steen, M. 2013. Codesign as a process of joint. Inquiry and Imagination 29(2): 16-28. http://www.mitpressjournals.org/doi/abs/10.1162/DESI_a_00207

Sultana, F. 2007. Reflexivity, positionality and participatory ethics: Negotiating fieldwork dilemmas in international research." ACME: An International E-Journal of Critical Geographies 6(3): 374 385. http://www.acme-journal.org/index.php/acme/article/view/786/2524/1/SM/pdf

Tintiangco-Cubales, A., P. N. Kiang and S. D. Museus. 2010. Praxis and power in the intersections of education praxis and power in the intersections of education. AAPI Nexus 8(1): v-xvii. 